\title{
WHO gives go ahead for experimental treatments to be used in Ebola outbreak
}

\author{
Anna Sayburn
}

London

The use of experimental vaccines and treatments in the outbreak of Ebola virus in west Africa is ethical so long as certain conditions are in place, a panel of 12 experts convened by the World Health Organization said in a statement on 12 August. $^{1}$

However, WHO said that it could not yet advise on how the very limited doses of treatments should be distributed or which patients should be prioritised for treatment. No doses remain of the experimental drug ZMapp, which was used on two healthcare workers from the United States, and no more are expected before the end of the year. The last doses have been shipped to Liberia to treat two doctors.

Marie-Paule Kieny, assistant director general of WHO, told a press conference that ZMapp was one of three types of treatment currently being evaluated, which had shown "promising" results in non-human primate trials. She said that WHO's statement did not mean people could test whatever treatments they wanted but that it applied only to treatments where early research had shown promise of benefit to humans.

WHO convened its panel of ethicists partly because of the treatment of two US citizens with ZMapp; although the drug had undergone animal studies, it had not been evaluated in humans. The panel said that ethical considerations must guide the use of experimental vaccines and treatments where efficacy and safety in humans had not been established.

"These [considerations] include transparency about all aspects of care, informed consent, freedom of choice, confidentiality, respect for the person, preservation of dignity and involvement of the community," the panel said in its statement. It added that anyone making treatments available had a "moral obligation" to ensure that data on their safety and efficacy were collected, shared, and made available for scientific evaluation.

Kieny listed three main types of treatment now under investigation for use in Ebola outbreaks: blood derived immunoglobulin treatments such as ZMapp; "more than three" antiviral drugs; and two potential vaccines, which she said were expected to move to human clinical trials within weeks. Although she said that the panel had agreed for experimental treatments to be used both in clinical trials and for "compassionate use" elsewhere, trials were the preferred option. "The priority is to push products into clinical trials as quickly as possible so we can scientifically assess their effects," said Kieny. She added that trials could be put together "relatively quickly" and that WHO hoped to see preliminary information about the efficacy and safety of some of the treatments by the end of the year.

When asked whether she thought ZMapp had worked in the two patients in whom it is known to have been used, Kieny said, "From what I have seen it has had a dramatic and rapid effect on their state of health. It seems highly probable that is due to the drug. But [unless there is a clinical trial] we will never know if it works or not."

The size, spread, and virulence of the current Ebola outbreak have made it the most severe on record. The usual systems of disease control, such as isolating patients and personal protection for health workers-which had brought previous outbreaks in Africa to a halt-had not worked, said Kieny. She said that this was partly because of weak healthcare systems in Liberia, Sierra Leone, and Guinea, the most severely affected countries. All three have recently emerged from civil war or conflict with much of their infrastructure damaged. ${ }^{2}$ It was partly the lack of success of these usual methods that had persuaded the ethicists that experimental treatments could be ethically used in these circumstances, said Kieny.

WHO figures released on 11 August showed new reports of Ebola cases and deaths. So far, 1176 confirmed cases and 660 deaths from the virus have occurred in the current outbreak. However, probable and suspected cases bring the totals to 1848 cases and 1013 deaths across Guinea, Liberia, Nigeria, and Sierra Leone. ${ }^{3}$

A Spanish healthcare worker who was infected in Liberia has also died. Media reports said that he was due to be treated with ZMapp, although it is unclear whether he actually received treatment before his death.

1 World Health Organization. Ethical considerations for use of unregistered interventions for Ebola viral disease (EVD): summary of the panel discussion. WHO statement. 12 August 2014. www.who.int/mediacentre/news/statements/2014/ebola-ethical-reviewsummary/en/.

2 World Health Organization. Barriers to rapid containment of the Ebola outbreak. WHO global alert and response. August 2014. www.who.int/csr/disease/ebola/overview-august2014/en/.

3 World Health Organization. Ebola virus disease update-west Africa. WHO Global alert and response. August 2014. www.who.int/csr/don/2014_08_11_ebola/en/. 